\title{
Remembering 40 Years, Plus or Minus
}

\author{
G. Gayle Stephens, MD
}

In July 1967, I went to work at Wesley Medical Center in Wichita, Kansas, with 2 tasks. One was to transform the existing Residency in General Practice into a new Willard Report-style Residency in Family Practice. The other was to organize a group of medical staff physicians to provide round-theclock professional services in the Wesley Emergency Department. I am pleased to report that both projects are functional today.

Presumptuous and cocky at age 39 and having lied to my wife about how much more orderly our lives would become, I moved my practice to a 2 -story bungalow on the Wesley campus. Seven hundred of my patients indicated their willingness to join me in this adventure and 1000 actually came to the new office during its first year of operation.

What I remember most clearly about this move was my sense of excitement and optimism about changes in medical care; it seemed the nation was prepared to reform its chronic problems-the doctor shortage, escalating costs, unjust distribution of medical services to rural and inner-city populations, and fragmentation of care among generalists and specialists. Our Sedgwick County Medical Society had led a successful campaign in 1962 to 1963 to immunize free of charge all willing citizens with the oral polio vaccine. The Medicare and Medicaid amendments had been passed by Congress in 1965, and the "Summer of Love" was happening in San Francisco.

Darker things were happening too. The Civil Rights Movement experienced "Bloody Sunday" in Selma; the Gulf of Tonkin Resolution passed in 1964; and 1968, an Annus Horribilis, was around the corner. Nevertheless, a light had gone on in my head in the fall of 1966 when I first read the famous reports (Willard, Millis, and Folsom) and saw a new

From the University of Alabama School of Medicine, Birmingham.

Funding: none.

Conflict of interest: none declared.

Corresponding author: G. Gayle Stephens, MD, 4300 Overlook Road, Birmingham, AL 35222 (E-mail: ggstephens@bellsouth.net). vision for general practice and doctoring families and wanted to participate in that.

\section{How It Began to Happen}

Dr. Jack Tiller, late father of recently assassinated George, was the volunteer director of Wesley's General Practice residency, and he graciously agreed to the transformation and my appointment as Director. I mention this here because the new Family Practice residencies were not created from nothing.

The Residency Review Committee for General Practice reported in 1965 that there were 198 approved graduate training programs. These were of 4 types: 2-year general practice residencies after internship in 165 hospitals offering 783 positions and $47 \%$ filled; 22 pilot programs of 2 years' duration, 14 of which offered obstetrics and 8 did not; and 15, 2-year internships. ${ }^{1}$

These programs were in 39 States, the District of Columbia, and Puerto Rico. Most were in Ohio (27); California, Michigan, and Pennsylvania (14 each); Illinois (12), and Virginia (10). Interestingly, 9 were in medical school settings and 6 were in military or United States Public Health Service settings. ${ }^{2}$ Moreover, 9 were included among 17 programs in development that accompanied the application for creating the American Board of Family Practice.

It is clear that what was going on in Wichita during 1967 was going on elsewhere and that important changes were occurring in medical education, not only for general practice but for graduate medical education among all specialties. I was responding to having read "Meeting the Challenge of Family Practice," the Willard Report, published in $1966^{3}$ (fortuitously, as I understand it) within 6 months of 2 other auspicious reports named for their chairmen: Folsom and Millis.,

It was not clear, however, who was meant to respond to these reports or how. Dr. Willard himself seemed rather tentative on this point in an article he wrote in the fournal of the American Medical Association in $1967 .^{6}$ He cited a letter from a medical school faculty member who raised the 
question of sponsorship and suggested "some joint venture would be desirable by a number of medical schools and hospitals."

It turned out that Executive Mac Cahal and the American Academy of General Practice (AAGP) was ahead of Willard. In his Annual Report of the Executive Director, published in March 1967, Cahal wrote that he had read all the "reports" and that the AAGP was ready with a core curriculum for the new residencies and even ready for a change of name of the AAGP to reflect its new educational mission. Coyly and modestly he proffered that the new name should properly be "American Academy of Medicine."7

Mr. Cahal was also ahead of his organization and its officers and members in actually implementing the changes called for in the Willard Report. Although the Folsom Report called for a personal physician for families and the Millis Report called for a new primary physician, neither specified that members of AAGP were meant to serve in these roles. In fact, Millis fancied a more grandiose model of the primary physician as one delivering comprehensive health care, acting as the "quarterback" of the team, the "company president," or the "senior partner in a law firm. " It would be arrogant, he said, to speak of these generalist roles derogatorily.

Nevertheless, generalist physicians of various academic backgrounds were raising their hands in response to the call. I discovered Lynn Carmichael in Miami, Florida, who was directing a straight internship in Family Practice with 12 positions filled in Jackson Memorial Hospital. Roger Lienke, a pediatrician, moved from Minnesota to Oklahoma City, where he was developing a residency at Mercy Hospital under the sponsorship of the University of Oklahoma School of Medicine. Eugene Farley was doing the same at Highland Hospital in Rochester, New York, as was Ian McWhinney at the University of Western Ontario in London, Ontario, Canada.

The new models of graduate education for family physicians called for a dedicated and identifiable "model family practice center," where residents, faculty, and other members of the team cared for defined groups of patients, providing comprehensive and continuing services on a regular basis, including an off-hours on-call schedule.

In addition to traditional clinical services for sick patients, we emphasized preventive services, super- vised counseling, with special awareness of the family as a unit of care; awareness and utilization of community resources; and appropriation of social and behavioral sciences. Although not mentioned in the Willard model, the clinical record was also being remodeled to the "problem-oriented" format as taught by Larry Weed ${ }^{8}$ and others.

In our 2-story Wesley bungalow and after 1970 in remodeled quarters at the former Sedgwick County Hospital, located in a low-income neighborhood, our staff included a medical social worker and we provided nutrition education in a demonstration kitchen, psychiatric supervision; we also had a strong liaison with a clinical pastoral educator. Residents and faculty served as high school team physicians, and they attended at a methadone clinic and a Methodist Urban Ministry house for street people, troubled teens, and the temporarily homeless.

Similar models of expanded family doctoring were springing up around the country under various sponsorships and financial arrangements. In retrospect, although these new residencies generally followed the Willard Report, a good deal of local creativity and financial support actually were being devoted to the creation of the bureaucracies of a new medical specialty. The American Board of Family Practice was approved in 1969, the first new primary board since 1949 . Basically, we were using the accreditation of the general practice residencies (already alluded to) until the Residency Review Committee for Family Practice first established new essentials for residency training.

\section{Unprecedented Success}

The availability of Board Certification was necessary, but not sufficient to explain what actually happened. It unleashed an unprecedented torrent of residency program development nationwide: 375 programs by 1975 . By comparison, pediatrics developed 150 programs in the decade of 1935 to 1945.

The catalyst for Family Practice, in my view, was the reform ethos of the 1960s that tapped into deep springs of American idealism and values-agrarianism, humanism, civil rights, feminism, and distributive justice. These ideals and values shaped the new discipline in ways not imagined by organized medicine. The new programs attracted faculty and medical students because they had a new vision of 
medical education and the roles of physicians and other health professionals. Nowhere was this change more visible than in the formation of the Society of Teachers of Family Medicine, which joined physicians with educators, psychologists, social workers, and administrators to learn how to implement the new strategies.

The nation's general practitioners discovered a deep affection in the public's opinion of their traditional virtues, and they had a reservoir of moral credibility when they said that they could become the physicians envisioned by Millis, Folsom, and Willard. This trust opened the public purses at federal, state, and local levels to finance the developing residencies. Each state has its own story of how it happened there.

Measured by the numbers of General Certificates issued by the Member Boards of the American Board of Medical Specialties, 1970 to 2007, Family Practice became the second largest specialty in the United States with 95,059 physicians, exceeded only by Internal Medicine (220,473 physicians) and followed by Pediatrics (89,578 physicians). ${ }^{9}$ The annual growth of Family Practice, now Family Medicine, accelerated during each decade, peaking in 1998 with 3619 certificants. The number exceeded 3000 annually until 2007, when it decreased to $2646 .^{9}$

There also was a decrease in applicants and matches for residency positions in Family Medicine in 2009, indicating that the number of annual certificants by the American Board of Family Medicine will continue to decline. ${ }^{10}$

\section{The Family Physician Workforce}

The universe of family physicians includes all living graduates of family practice residencies, but it cannot be presumed that all are members of the American Academy of Family Physicians (AAFP) or that they are all practicing family medicine. Nor can it be assumed that all graduates of residencies are Board certified even though they are members of AAFP. Moreover, there is a diminishing number of older family physicians who are or were board certified but who did not complete a family practice residency. Given these contingencies, the data as of December 31,2007, as reported by the AAFP, is shown
Table 1. Living Graduates of Family Medicine Residencies from 1969 to $2007(\mathrm{n}=\mathbf{8 3 , 6 1 6})$

American Board of Family Medicine Diplomates 83.5

Women

International medical graduates

Doctors of Osteopathy

Values provided as \%.

in Table $1 .^{11}$ These numbers have steadily evolved during 4 decades in favor of more women $(51.8 \%)$; international medical graduates (35.6\%); and doctors of osteopathy (17.5\%). No data regarding minority status is given. ${ }^{11}$

The total AAFP membership as of December 31, 2008, was 94,614; of this total, 62, 112 were active members. A survey was conducted by the AAFP to assess practice profiles of family physicians that completed a family medicine residency. ${ }^{11}$ There were 29,083 respondents, including 26,773 residency graduates and 2,310 nongraduates. The nongraduates were more likely to be self employed; engaged in solo practice; and have more income from fees, contracts, and Medicare.

The demography of family physicians accounted for by the AAFP is representative of that of physicians throughout the United States. Their qualifications by formal graduate education and Board certification are comparable, and their practice arrangements and range of services are consistent with the goals of the Willard report. They comprise an important proportion (perhaps 30\%) of full-time equivalent physicians in clinical practice of primary care, which includes general and family practice, general internal medicine, and general pediatrics. $^{12}$

\section{The End of the Beginning}

It is worrisome to observe the recent decline in medical students' interest in family medicine, as evidenced by results of the National Residency Matching Program. How are we to account for the decreasing rate of growth in the training of family physicians after its first decade, followed most recently by actual attrition?

That and other problems were recognized at the 35 th Anniversary of the then-American Board of Family Practice in 2004. Dr. Puffer presented 2 slides titled "The Gathering Storm," in which he listed these items ${ }^{13}$ : 
- Reimbursement continues to favor proceduralists

- Patients prefer direct access to specialists

- Health maintenance organizations retreat from the concept of gatekeepers

- Public backlash toward managed care (and, by association, primary care)

- Increasing liability costs

- Increased strategies to reduce costs

- Increased patient volume

- Increased administrative responsibility

- Advent of the hospitalist

- Increasing numbers of nurse practitioners and physician assistants trained to deliver primary care

If these items were not enough, a commissioned national survey by the Greenfield Consulting Group reported that family physicians had become anonymous. ${ }^{14}$

"Family physicians are not well recognized by the public for what they are and what they do. Patients have a hard time differentiating family medicine from other primary care physician specialties, notably not distinguishing clearly between family medicine and general internal medicine. Indeed the words 'family' and 'practitioner' were often found to confuse people and suggested to some that family physicians lack scientific background and competence" (J.C. Puffer, personal communication).

Among the wounds I licked after the lost fight for health care reform in 1994 was the abrasive accusation that primary care is no bargain because its practice is inferior. My local newspaper ran an editorial titled "In Praise of Specialists," and cited 2 articles and an editorial from the New England Fournal of Medicine. One was a survey of 1211 physicians in New York and Texas comparing self-reports of cardiologists', internists', and family physicians' prescribing practices for 5 drugs to patients having acute myocardial infarctions. The survey showed that cardiologists were more likely than internists and family physicians to prescribe thrombolytic agents, $\beta$-blockers, and aspirin, and that cardiologists were less likely to prescribe lidocaine and diltiazem. The differences between cardiologists and family physicians for these prescription practices ranged between $8.9 \%$ and $24.4 \%$, with internists in between. ${ }^{15}$

The second study compared quality of life measures for Canadian and US patients 1 year after myocardial infarction. There was a statistical advantage but no survival benefit for US patients, who also had twice the interventions than their Canadian counterparts. ${ }^{16}$

The New England Fournal of Medicine editorial commented on both studies and wrote: "We are now making a 180-degree turn on the matter of incentives, moving from too much care in fee-forservice practice to too little in managed care. If we are not smart enough to protect patients' access to some of our best physicians, we will all be losers." ${ }^{\prime 7}$

My local paper said that specialists, for all their big fees and "Star Trek" equipment, do deliver better care and concluded that "feckless parsimony and undertreated patients don't sound to us like much of a reform."

The putative clinical inferiority of general practitioners is an old theme in US medicine. It is simply irresponsible and uninformed to impugn generalist care without taking into account all the recent literature about comparative practice. Marginal differences in self-reported prescribing habits and minor quality of life measurements without survival benefit are incommensurate with morbidity and mortality from lack of access to medical care, inadequate preventive care, iatrogenic harm, and inattention to personal and social factors in the genesis of illness. "Feckless parsimony" is not yet in the same league with extravagant overindulgence and is not yet the worst or most fearful characteristic of US medicine.

Resistance to low-tech medicine and an inordinate love of imaging, surgery, and invasive procedures are not the only barriers to prudent comprehensive care and personal doctoring. The "gathering storm" that Puffer identified in $2004^{13}$ actually began in the 1980s, a turbulent decade for the nation as well as for the medical care system.

The 1980s began with a severe recession that took up almost 2 years (January to June 1980, and July 1981 to November 1982). Interest rates were high; gross domestic product was negative for 6 of 12 quarters; the lowest quarterly drop in GDP, $7.8 \%$, was the worst since the Great Depression; and unemployment peaked at $10.8 \%$ and remained at more than $10 \%$ for 10 months (http:// useconomy.about.com/od/grossdomesticproduct/ $\mathrm{a} /$ recession_histo.htm? $\mathrm{p}=1$ ). By comparison this recession was worse in many respects than the current economic crisis. 
Within the climate of economic constraints the Federal government acted to contain the Medicare budget by regulating hospital utilization and putting a 28-month freeze on physicians' fees. This was the era of diagnosis-related groups, resource-based relative value scales, health maintenance organizations, preferred provider organizations, and other provocative acronyms as the government, doctors, and managed care organizations tangled over costs, prices, and regulations. Investor-owned corporations became dominant players as Federal policies promoted competition in the medical supermarket. It was the fantasy of Paul Ellwood at Interstudy that the "cottage industry" of 400,000 "firms" owned by individual physicians might merge into, say, 25 national firms serving the entire population. Indeed, in 1985, there were 393 health maintenance organizations with 18.9 million members. ${ }^{18}$

The decade was especially discouraging for primary care specialties who protested, mostly in vain, that payment methods discriminated against them in favor of procedure-oriented specialists. In 1982, mean take-home income for family physicians was approximately half of the $\$ 135,000$ mean pretax earnings of surgical subspecialists, and by 1988 it was approximately $40 \%{ }^{19}$ (and destined to decrease by comparison).

Medical student debt as a deterrent to choosing a primary care career must be understood in this context of expected earnings. In the 1980s there was a measureable shift in choice of specialty among senior graduating medical students. The biggest losers were family practice and internal medicine, with lesser losses for the specialties of pediatrics, surgery, and obstetrics. The winners were radiology, anesthesiology, emergency medicine, physical medicine, and psychiatry. ${ }^{10}$

Incidentally, there was a decrease in the number of applicants to medical schools, from approximately 36,000 in 1980 to approximately 26,000 in 1988. This did not affect the number of enrollees, which remained steady at approximately 16,000. I do not attribute this to reduced interest in primary care, but it suggests disenchantment with medicine as a profession.

\section{The Future of Family Medicine}

The task of reinvigorating family medicine feels to me very much like the same task that was faced in the 1960s. And our strategies seem very similar; ie, to improve family doctors through education, redesign the system of medical care in which they work, and improve quality and scope of services. The Future of Family Medicine Project is a great deal more sophisticated than the Willard Report, but the stated goal- "to ... transform and renew the discipline of family medicine to meet the needs of patients in a changing health care environment—is familiar, developmental, and congruent. ${ }^{14}$ The presumption, and possibly the flaw, of both documents is that achieving the stated goals lies within our power. Perhaps one of the reasons we chose to implement Willard's ideas instead of Folsom's in the 1960s was that it seemed possible. The Folsom ideals for personal physicians were more robust and perhaps more durable. But there is more.

During the last 40 years American medicine has existed in and contributed to a toxic cultural and political environment that is inimical to the goals of family medicine. Iago Galdston, referring to the failure of Hippocratic medicine to stem the Black Plague, blamed the "insalubrious moral ecology" of medieval cities, where raw sewage ran in the streets and rats and fleas propagated in the straw floors of people's homes. The comparison is extreme but not bizarre.

Family physicians and their professional organizations have usually not supported the reforms in medical care that would facilitate their goals and favor their best interests. From 1949 through 1964, the Congress of Delegates opposed at least 6 times any resolution for "any form of compulsory federal health insurance or any system of political medicine designated for national bureaucratic control." The wording of the various resolutions varies but the opposition never wavers. $^{20}$

In 1988, however, the Congress of Delegates approved a recommendation from the president elect of the AAFP to develop and promote a health policy for uninsured and underinsured citizens to have access to a basic range of health services. This resulted in a very thoughtful proposal titled " $\mathrm{Rx}$ for Health: the Family Physicians' Access Plan," and it was adopted by the AAFP Congress of Delegates in October 1992. ${ }^{21}$

I do not know how this enlightened proposal was shopped in Washington, D.C., with Clinton's Health Plan or in Congress; nevertheless the AAFP leadership changed its rhetoric if not its collective mind. 
Now we are engaged in another time of troubling of the Pool at Bethesda-a time of opportunity as occurred in the mid-1960s, when the elderly and the impoverished were included. My hope is that family physicians will support reform now as they did not in 1965. If reform occurs they might get a chance to find out whether their goals of transforming and redesigning the medical home will really work.

In 1975 I used what now seems an infelicitous term- "patient management"- to describe what I thought was the essential and irreducible center of family doctoring. I did not foresee then that the word "manage" and its cognates would be expropriated by bureaucratic and economic systems for more limited and specific uses, as in managed care, case managers, and practice management. Neither did I anticipate that it would take on paternalistic overtones.

Yet, despite these semantic ambiguities, something like patient management is at or very near the center of what family physicians know and do. If the centerpiece of surgery is the operation and cutting is its method; if the centerpiece of radiology is the image and looking is its method; the centerpiece of family practice is the durable clinical relationship and listening is its method. Whatever we can do to preserve and enhance this exchange is good.

\section{References}

1. AAGP transactions of the Congress of Delegates, 1965. Accessed through the Archives of the History of Family Medicine. American Academy of Family Physicians, Leawood, KS.

2. AMA Directory of Approved Internships and Residencies. Chicago: American Medical Association; 1965.

3. American Medical Association. Meeting the challenge of family practice. The report of the Ad Hoc Committee on Education for Family Practice of the Council of Medical Education. Chicago: American Medical Association; 1966.

4. Folsom MB, American Public Health Association and National Health Council. Health is a community affair. Report of the National Commission on Community Health Services. Boston: Harvard University Press; 1967.

5. The Graduate Education of Physicians. The report of the Citizens Commission on Graduate Medical Education. Chicago: American Medical Association; 1966.

6. Willard WR. Rational responses to meeting the challenge of family practice. JAMA 1967;201:122-8.

7. Cahal MF. Annual Report of Executive Director, GP. Kansas City: American Academy of General Practice; March 1967: 189-97.
8. Weed LL. Medical records that guide and teach (part II). N Engl J Med 1968;278:652-7.

9. American Board of Medical Specialties (ABMS). Certification history: ABMS Member Board general certificates issued by decade, 1930-2007. In: ABMS Annual Report and Reference Handbook. Evanston, IL: American Board of Medical Specialties Foundation; 2008: 1,8 .

10. National Residency Matching Program, Association of American Medical Colleges. Charting outcomes in the match: characteristics of applicants who matched to their preferred specialty in the 2009 main residency match. Available at http://www.nrmp.org/ data/chartingoutcomes2009v3.pdf. Accessed 16 January 2010.

11. American Academy of Family Physicians. Facts about family medicine. Available at http://www.aafp.org/online/en/home/aboutus/specialty/facts.html. Accessed 12 February 2010.

12. United States Department of Health and Human Resources, Health Resources and Services Administration, Bureau of Health Professions. Physician supply and demand projection of 2020. Exhibit 12: fulltime equivalent supply of physicians in clinical practice. Washington, D.C.: United States Department of Health and Human Resources; 2006: 14.

13. Puffer JC. The American Board of Family Physicians: thirty-five years of promoting quality. Program booklet for The $35^{\text {th }}$ Anniversary Celebration of the American Board of Family Practice. Lexington, KY: American Board of Family Physicians; 2004.

14. Martin JC, Avant RF, Bowman MA, et al. The Future of Family Medicine: a collaborative project of the family medicine community. Ann Fam Med 2004;2(Suppl 1):S3-32.

15. Ayanian JZ, Hauptman PJ, Guadagnoli E, et al. Knowledge and practices of generalist and specialist physicians regarding drug therapy for acute myocardial infarction. N Engl J Med 1994;331:1136-42.

16. Mark DB, Naylor CD, Hlatky MA, et al. Use of medical resources and quality of life after acute myocardial infarction in Canada and the United States. N Engl J Med 1994;331:1130-5.

17. Kassirer JP. Access to specialty care. N Engl J Med 1994:331:1151-3.

18. HMO, PPO growth booms. Am Med News 1986; 29:18.

19. Physicians become victims of the bottom line. Am Med News 1990;33:4.

20. AAGP transactions of the Congress of Delegates, 1948-1965. Accessed through the Archives of the History of Family Medicine. American Academy of Family Physicians, Leawood, KS.

21. AAFP transactions of the Congress of Delegates, 1988-1994. Accessed through the Archives of the History of Family Medicine. American Academy of Family Physicians, Leawood, KS. 